\title{
The pathway to induced abortion: women's experiences and general practitioner attitudes
}

\author{
Sarah Finnie, Robbie Foy, Jean Mather
}

\begin{abstract}
Objective Secondary care services are struggling to manage demand for induced abortion, but less is known about what scope exists to improve the primary care of women requiring abortion. The study objective was to identify service-related delays and barriers faced by women seeking abortion care.
\end{abstract}

Methods The study comprised case note review and cross-sectional surveys conducted in South Durham in the North East of England, UK. We surveyed and reviewed the case notes of women attending two fertility control clinics. We also surveyed general practitioners (GPs) who referred women to these clinics. The outcomes were waiting times within the pathway to induced abortion, women's rating of care, GPs' attitudes and self-reported practice.

Results Of 210 women surveyed, 132 (63\%) responded. Of 107 referred by GPs, 16 (15\%) had to make a second appointment with another GP willing to refer them and 34 $(32 \%)$ waited two or more days to receive a date for their hospital appointment. The national standard waiting time of 3 weeks from first appointment with the referring doctor to the procedure was achieved for $56 / 127$ women (44\%; $95 \% \mathrm{Cl}, 35-53)$. Women rated global satisfaction, provision of information and staff interaction more highly in secondary than primary care. Of 170 GPs surveyed, 140 $(82 \%)$ responded; 33 (24\%) considered themselves 'broadly anti-abortion'.

Conclusions Women face delays in accessing induced abortion care, both before and after referral from primary care. Whilst scope exists for improving quality of care and access within present service configurations, alternative approaches that bypass traditional gatekeepers to abortion care should be evaluated.

J Fam Plann Reprod Health Care 2006; 32(1): 15-18 (Accepted 20 October 2005)

\section{Key message points}

- Access to National Health Service induced abortion care varies considerably throughout the UK.

- Women seeking access to abortion services want their general practitioner to treat them with respect, provide information and arrange prompt referral.

- Women seeking abortion experience barriers that will require alternative models of care to overcome. Some of these barriers contribute to delay, though their most important effect is on the patient experience.

Neasham Road Surgery, Darlington, UK

Sarah Finnie, MRCGP, MSc, General Practitioner

Centre for Health Services Research, University of Newcastle-upon-Tyne, Newcastle-upon-Tyne, UK Robbie Foy, MRCGP, PhD, Clinical Senior Lecturer in Primary Care

Durham Dales Primary Care Trust, Bishop Auckland, UK Jean Mather, MB BS, MFFP, Consultant in Family Planning and Reproductive Health Care

Correspondence to: Dr Robbie Foy, Centre for Health Services Research, University of Newcastle-upon-Tyne, 21 Claremont Place, Newcastle-upon-Tyne NE2 4AA, UK. Tel: +44 (0) 191222 7214. Fax: +44 (0) 191222 6043. E-mail: r.c.foy@ncl.ac.uk

\section{Introduction}

Induced abortion is the most commonly performed gynaecological procedure, with 181600 carried out for women resident in England and Wales in 2003. ${ }^{1}$ Some $80 \%$ of abortions are performed in the National Health Service (NHS), with the majority being referred by general practitioners (GPs). Rapid access to abortion care is important to reduce distress and complications associated with procedures undertaken at higher gestations. ${ }^{2,3}$ The Government's sexual health strategy states that no woman should wait longer than 3 weeks from the first appointment with the referring doctor to the procedure, ${ }^{4}$ a standard supported by professional guidelines. ${ }^{5}$ It is recognised that secondary care services are struggling to meet this target, but less is known about what scope exists to improve the primary care of women requiring abortion. 6 We set out to identify service-related delays and barriers faced by women seeking abortion care.

\section{Methods}

Study design and setting

We undertook a survey and case note review of women seeking NHS abortions to assess their experiences and waiting times. We also surveyed GPs about their attitudes towards and roles in providing abortion care. The study took place in South Durham, in the North East of England, UK, which has a population of 277200 covered by three Primary Care Trusts (PCTs). Surveyed GPs provided care for the population from which our sample of women was drawn.

\section{Women's survey and case note review}

We invited women attending two fertility control (induced abortion) hospital clinics in South Durham to take part in the study during a 4-month period in 2003. Following consent, a family planning doctor (J.M.) gathered information about the referral process via structured, faceto-face interviews. She recorded information about the specialty of referring doctor, how women were given abortion clinic appointments, and waiting times at each stage of the pathway. Women then completed the remainder of the questionnaire themselves at the end of the clinic. This section included 12 statements each about experiences at both referral and the clinic. Respondents indicated how strongly they agreed or disagreed with statements on a fivepoint Likert scale. The questions, previously demonstrated to have good internal consistency, covered information, staff interaction, the counselling process and global satisfaction. ${ }^{7}$ Completed questionnaires did not include patient identifying data to ensure confidentiality but were coded for linking purposes. Hospital secretaries reviewed the women's case notes several weeks later to obtain further information about waiting times. We took the date of medical abortion as the day of administration of mifepristone. The wait from first appointment with the referring doctor to further appointments and abortion procedures was calculated for each woman using appointment dates women gave in the survey and dates recorded in the case notes.

\section{GP survey}

The questionnaire explored attitudes to abortion, and referral practices and arrangements. ${ }^{8}$ Following pre-testing 


\section{ARTICLE}

Table 1 Characteristics of women having an abortion

\begin{tabular}{|c|c|c|c|c|}
\hline \multirow[t]{2}{*}{ Characteristic } & \multicolumn{2}{|c|}{$\begin{array}{l}\text { Women attending } \\
\text { Darlington Memorial } \\
\text { and Bishop Auckland } \\
\text { clinics (study group) }\end{array}$} & \multicolumn{2}{|c|}{$\begin{array}{l}\text { Total referrals by South } \\
\text { Durham Primary Care } \\
\text { Trusts in } 2002\end{array}$} \\
\hline & $n$ & $\%$ & $n$ & $\%$ \\
\hline All & 132 & & 599 & \\
\hline \multicolumn{5}{|l|}{ Age (years) } \\
\hline Under 16 & 3 & 2 & 19 & 3 \\
\hline $16-19$ & 44 & 35 & 140 & 23 \\
\hline $20-24$ & 35 & 28 & 168 & 28 \\
\hline $25-29$ & 19 & 15 & 104 & 17 \\
\hline $30-34$ & 15 & 12 & 94 & 16 \\
\hline $35-39$ & 9 & 7 & 63 & 11 \\
\hline$\geq 40$ & 2 & 2 & 11 & 2 \\
\hline $\begin{array}{l}\text { Unknown/not } \\
\text { applicable }\end{array}$ & 5 & 4 & 0 & 0 \\
\hline \multicolumn{5}{|c|}{ Gestation (weeks) } \\
\hline$<10$ & 76 & 60 & 352 & 59 \\
\hline $10-12$ & 39 & 31 & 170 & 28 \\
\hline $13-19^{b}$ & 11 & 9 & 70 & 12 \\
\hline$\geq 20^{\mathrm{b}}$ & 0 & 0 & 3 & 1 \\
\hline $\begin{array}{l}\text { Unknown/not } \\
\text { applicable }^{\mathrm{c}}\end{array}$ & 6 & 5 & 0 & 0 \\
\hline
\end{tabular}

ancludes two women for whom data were missing and three women for whom the outcome was other than abortion.

bClinics in study only performed procedure up to a maximum of 16 weeks' gestation.

cIncludes three women for whom data were missing and three women for whom the outcome was other than abortion.

on a small convenience sample and refinement, the questionnaires were posted in early 2003 followed by up to two reminders for non-respondents.

\section{Sample size}

A total of 136 women respondents were required to estimate the proportion having abortions within 3 weeks of referral with a $95 \%$ CI of $6 \%$, based on a compliance level of $85 \%$ measured elsewhere in the UK. ${ }^{9}$ A sample size of 110 GPs was required to estimate how many agreed with the statement that 'all women should have access to NHS abortion services' with a $95 \%$ CI of 5\%, based upon $75 \%$ agreement. $^{8}$

Table 2 Characteristics of general practitioner respondents

\begin{tabular}{|c|c|c|c|c|}
\hline \multirow[t]{2}{*}{ Characteristic } & \multicolumn{2}{|c|}{$\begin{array}{l}\text { Study group GPs } \\
\text { (recruited from South } \\
\text { Durham PCTs) }\end{array}$} & \multicolumn{2}{|c|}{$\begin{array}{l}\text { County Durham and } \\
\text { Darlington GPs (North } \\
\text { and South Durham } \\
\text { PCTs) }\end{array}$} \\
\hline & $n$ & $\%$ & $n$ & $\%$ \\
\hline All & 140 & & 343 & \\
\hline \multicolumn{5}{|l|}{ Gender } \\
\hline Female & 45 & 32 & 99 & 29 \\
\hline Male & 95 & 68 & 244 & 71 \\
\hline \multicolumn{5}{|l|}{ Age (years) } \\
\hline $25-34$ & 19 & 14 & 44 & 13 \\
\hline $35-44$ & 65 & 46 & 158 & 46 \\
\hline $45-54$ & 45 & 32 & 117 & 34 \\
\hline$\geq 5+$ & 11 & 8 & 24 & 7 \\
\hline Trainer & 16 & 12 & 30 & 9 \\
\hline \multicolumn{5}{|l|}{ Qualifications } \\
\hline MRCGP & 99 & 71 & 83 & 24 \\
\hline DRCOG & 73 & 52 & 67 & 20 \\
\hline DFFP/MFFP & 46 & 33 & 28 & 8 \\
\hline \multicolumn{5}{|l|}{$\begin{array}{l}\text { Years since } \\
\text { qualified as a GP }\end{array}$} \\
\hline $0-9$ & 37 & 26 & & \\
\hline $10-19$ & 58 & 41 & & \\
\hline $20-29$ & 36 & 26 & & \\
\hline$\geq 30$ & 9 & 6 & & \\
\hline
\end{tabular}

DFFP/MFFP, Diploma/Membership of the Faculty of Family Planning and Reproductive Health Care; DRCOG, Diploma of the Royal College of Obstetricians and Gynaecologists; GP, general practitioner; MRCGP, Membership of the Royal College of General Practitioners; PCT, Primary Care Trust.
Table 3 Access to abortion pathway ( $\mathrm{n}=132$ women)

\begin{tabular}{|c|c|c|c|}
\hline Parameter & $\begin{array}{l}\text { Women } \\
(n)\end{array}$ & $\begin{array}{l}\text { Proportion } \\
(n)\end{array}$ & $\begin{array}{l}95 \% \\
\mathrm{CI}\end{array}$ \\
\hline \multicolumn{4}{|l|}{ Referred by ${ }^{a}$} \\
\hline General practitioner & 107 & 82 & $75-88$ \\
\hline Family planning doctor & 22 & 17 & \\
\hline Other & 1 & 1 & \\
\hline $\begin{array}{l}\text { Appointment with referring doctor } \\
\text { within } 2 \text { days }\end{array}$ & 76 & 59 & $50-67$ \\
\hline \multicolumn{4}{|c|}{$\begin{array}{l}\text { Receipt of fertility control clinic (hospital) } \\
\text { appointment }{ }^{b}\end{array}$} \\
\hline At time of consultation & 61 & 47 & $38-56$ \\
\hline Later same day & 13 & 10 & \\
\hline Next working day & 17 & 13 & \\
\hline Two or more days later & 38 & 30 & \\
\hline $\begin{array}{l}\text { Fertility control clinic appointment } \\
\text { within } 7 \text { days of appointment with } \\
\text { referring doctor }\end{array}$ & 3 & 2 & $0-7$ \\
\hline $\begin{array}{l}\text { Procedure within } 14 \text { days of fertility } \\
\text { control clinic appointment }\end{array}$ & 123 & 97 & $92-99$ \\
\hline $\begin{array}{l}\text { Procedure within } 21 \text { days of first } \\
\text { appointment with referring doctor }\end{array}$ & 56 & 44 & $35-53$ \\
\hline
\end{tabular}

aExcludes two women for whom details not known.

bExcludes three women for whom details not known.

\section{Data entry and analysis}

Data were entered into and analysed using Minitab. We used confidence interval analysis for CIs for differences in proportions of paired samples. ${ }^{10}$ We combined ratings for women's experiences of care and GP opinions into two categories: 'strongly agree and agree' and 'strongly disagree, disagree and neither agree nor disagree'.

\section{Ethical approval}

The study was approved by County Durham and Darlington Local Research Ethics Committee.

\section{Results}

\section{Response rates and characteristics}

One hundred and thirty-two (63\%) of 210 eligible women agreed to participate. Of these, $130(62 \%)$ completed the face-to-face interview and had their case records reviewed whilst $116(55 \%)$ returned the self-completion questionnaire. Participants were similar in age and gestation of abortion to all recorded abortions in South Durham in 2002, except the proportion of 15-19-year-olds was higher in the study. ${ }^{11}$ Seventy-six $(60 \%)$ abortions were performed at less than 10 weeks' gestation and 11 $(9 \%)$ over 12 weeks' gestation (Table 1). One hundred and forty $(82 \%)$ of 170 GPs completed questionnaires. Respondent characteristics were similar to all GPs in County Durham and Darlington (Table 2).

\section{The pathway to abortion care}

Arranging referral. According to the survey of women, most $(107 ; 82 \%)$ were referred by GPs (Table 3). Fifty-six $(52 \%)$ of these women were seen within 48 hours of making an appointment compared with 20/23 (91\%) mainly referred by family planning clinics $(95 \%$ CI for difference, 18-50). For women seeing GPs, 16 (15\%) had to make a second appointment with another GP willing to refer them and $34(32 \%)$ waited two or more days to receive a date for their fertility control clinic appointment.

Waiting times. The median wait from first appointment with the referring doctor to attending the fertility control clinic was 21 [interquartile range (IQR), 16-26] days and to having an abortion was 23 (IQR, 19-29) days. Less than half $(44 \%)$ had abortions within 21 days of their first appointment with the referring doctor. Only 2\% had fertility control clinic appointments within 7 days of the 
Box 1: Selected comments made by women in the study

- "The first visit to the doctor's regarding my request was traumatic. She sent me away due to her beliefs. She did however arrange another appointment with $\mathrm{Dr} X$. He was excellent."

- "The doctor at X surgery really hurt my feelings. I asked for help, not to be hurt. If she doesn't agree with termination then she shouldn't have explained it the way she did."

- "When I went to see my GP who referred me he did not explain anything to me. The doctor asked me to wait in the waiting room while he made an appointment, following this a nurse then came over to me with my appointment wrote on a scrap of paper and I left the doctor's surgery. During the weeks up to my appointment at the clinic I worried and had to phone the NHS helpline to ask for some information as nothing was explained."

first appointment with the referring doctor. The majority (97\%) of women had abortion procedures within 14 days of fertility control clinic appointments.

\section{Women's experience of care}

According to the questionnaire survey, women's experience of care was generally positive (Table 4). However, global satisfaction and ratings for provision of information and staff interaction were lower from primary than secondary care. We were struck by the comments women made to a final open-ended question and have included selected examples in Box 1.

\section{GPs' provision of care and attitudes}

According to the survey of GPs, most $(126 ; 90 \%)$ indicated that they refer women themselves, 71 (51\%) usually arranging referral during the first appointment. The remainder asked women to see an alternative GP within the practice. Approximately one-third each of GPs did not provide on-site pregnancy testing $(52 ; 37 \%)$ and believed they had insufficient information about abortion services (43; 32\%). Most (118; 93\%) reported referring under-16s who attend with a parent or guardian and request an abortion. Fewer $(72 ; 52 \%)$ would refer unaccompanied under-16s; 34 did not answer this question. About onequarter (24\%) of GPs considered themselves to be 'broadly anti-abortion' but fewer (5\%) agreed that the NHS should not fund abortion services (Table 5).

\section{Discussion}

Less than half of the women we studied had an abortion within the national standard of 3 weeks from their first appointment with their referring doctor. Much of this delay may be related to limited secondary care capacity. However, women also experience barriers in primary care, mainly because of organisational and attitudinal factors.
Women were also relatively dissatisfied with their primary care, and in particular the way staff treated them and the information they were given.

By following women's progress in the pathway to induced abortion we were able to identify steps and processes potentially amenable to change. The findings on waiting times compare poorly with Scotland, where $93 \%$ of women wait no longer than 3 weeks from referral to the time of their abortion. ${ }^{9}$ However, we measured the wait from the first appointment rather than referral, in line with the sexual health strategy standard.

Given the sensitivity of the topic, the response rates for both women $(63 \%)$ and GPs $(82 \%)$ compare favourably with surveys conducted elsewhere.7-9,12 Our sample characteristics were representative of their respective populations, although response bias potentially remains a problem. Although we only examined experience within three PCTs, national audits and performance indicators strongly suggest the picture is similar elsewhere.6,13 Furthermore, the sampling strategy excluded women who sought access to abortion services in NHS hospitals outside the area or in the private sector, possibly underrepresenting particular barriers to local NHS services. We also do not know how many women consulted GPs and were inappropriately deterred from seeking abortions.

Our methods had three main limitations. First, estimated waiting times relied on women's reports and may have been affected by recall bias. It was also not possible to differentiate between first appointment available and the first that a woman could actually attend. Second, given that questionnaires were administered by a member of staff in fertility control clinics, 'halo' effects could account for women's higher ratings of secondary care. Third, the doctor giving out questionnaires was aware that she was participating in a study (and would have been subject to Hawthorne effects) unlike referring doctors. However, a subgroup analysis suggested that women were globally less satisfied with GP care compared with family planning clinics. Compared to fertility control clinic care, $25 \%$ (14-36\%) more women referred by GPs thought their initial medical care could have been better compared to none $(-23 \%$ to $23 \%)$ referred by family planning doctors. This provides evidence that lower ratings of GP care are unlikely to be solely because they represented the first (and most traumatic) consultation with a health professional.

Women seeking abortions value being treated with respect, given appropriate information and referred promptly. ${ }^{14-16}$ Dedicated abortion clinics are associated with high levels of patient satisfaction; supportive attitudes of staff may be a key factor. 7,17

Table 4 Women's experience of care $(\mathrm{n}=132)$

\begin{tabular}{|c|c|c|c|c|}
\hline \multirow[t]{2}{*}{ Parameter } & \multicolumn{2}{|c|}{ Agreement with statement (\%) } & \multirow[t]{2}{*}{ Difference } & \multirow[t]{2}{*}{$95 \% \mathrm{CI}$} \\
\hline & At fertility control clinic & With referring doctor & & \\
\hline \multicolumn{5}{|l|}{ Information } \\
\hline I was given enough information & 97 & 57 & 41 & $31-51$ \\
\hline The information I was given was easy to understand & 97 & 67 & 31 & $22-40$ \\
\hline \multicolumn{5}{|l|}{ Staff interaction } \\
\hline The clinical care I received was excellent & 95 & 61 & 33 & $23-43$ \\
\hline My confidentiality was respected & 99 & 99 & 0 & -4 to 4 \\
\hline The staff treated me with respect & 97 & 82 & 15 & $7-24$ \\
\hline The staff were professional and thorough & 96 & 77 & 19 & $1-28$ \\
\hline The staff treated me as a whole person & 95 & 85 & 10 & $2-18$ \\
\hline The staff weren't afraid to discuss emotional issues & 84 & 68 & 17 & $7-27$ \\
\hline \multicolumn{5}{|l|}{ Counselling process } \\
\hline There was too much emotional talk & 6 & 11 & -5 & -11 to 2 \\
\hline There was too much medical talk & 7 & 4 & 3 & -3 to 9 \\
\hline The staff asked too many questions & 8 & 5 & 3 & -4 to 9 \\
\hline \multicolumn{5}{|l|}{ Global measure } \\
\hline $\begin{array}{l}\text { There are some things about the medical care I received } \\
\text { that could be better }\end{array}$ & 14 & 35 & -21 & -30 to -12 \\
\hline
\end{tabular}




\section{ARTICLE}

Table 5 General practitioner opinions about abortion $(\mathrm{n}=140)$

\begin{tabular}{|c|c|c|c|c|c|c|c|}
\hline \multirow[t]{2}{*}{ Opinion } & \multicolumn{5}{|c|}{ General practitioners $[n(\%)]$} & \multirow{2}{*}{$\begin{array}{l}\text { Overall } \\
\text { agree }(\%)\end{array}$} & \multirow[t]{2}{*}{$95 \% \mathrm{CI}$} \\
\hline & $\begin{array}{l}\text { Strongly } \\
\text { disagree }\end{array}$ & Disagree & Neither & Agree & $\begin{array}{l}\text { Strongly } \\
\text { agree }\end{array}$ & & \\
\hline $\begin{array}{l}\text { If a general practitioner conscientiously objects to abortion } \\
\text { he/she should be required to declare this to a woman seeking } \\
\text { access to abortion services. }\end{array}$ & $3(2)$ & $13(9)$ & $16(12)$ & $47(34)$ & $60(43)$ & 77 & $69-84$ \\
\hline All women should have access to NHS abortion facilities. & $4(3)$ & $8(6)$ & $11(8)$ & $48(35)$ & $67(48)$ & 83 & $76-89$ \\
\hline $\begin{array}{l}\text { The } 1967 \text { Abortion Act, requiring the written consent of two } \\
\text { doctors before any legal abortion can proceed, is appropriate } \\
\text { and should remain unchanged. }\end{array}$ & $9(6)$ & $17(12)$ & $17(12)$ & $71(51)$ & $26(18)$ & 69 & $61-77$ \\
\hline Abortion services should not be funded by the NHS. & $64(46)$ & $51(36)$ & $18(13)$ & $5(4)$ & $2(1)$ & 5 & $2-10$ \\
\hline $\begin{array}{l}\text { The } 1967 \text { Abortion Act should be amended to provide a woman } \\
\text { with the right to choose to have an abortion in the first } 14 \\
\text { weeks of pregnancy, after consultation with a doctor. }\end{array}$ & $10(7)$ & $35(25)$ & $48(35)$ & $36(26)$ & $9(7)$ & 33 & $25-41$ \\
\hline $\begin{array}{l}\text { The } 1967 \text { Abortion Act places an unreasonable burden on the } \\
\text { general practitioner. }\end{array}$ & $13(9)$ & 74 (53) & $36(26)$ & $14(10)$ & $3(2)$ & 12 & $7-19$ \\
\hline
\end{tabular}

Efforts to raise standards of abortion care have tended to focus around the delivery of secondary care.4,18 Our findings highlight the potential to improve women's experiences of primary care. Yet GPs have limited time and resources to support and refer women seeking abortions. Action is needed through PCT development plans, including staff development and improved availability and use of both on-site pregnancy testing and high-quality information for GPs and their patients. ${ }^{19}$ Measures to reduce the wait for initial GP appointments already appear to be working. ${ }^{20}$

Despite such measures, many women may continue to experience delays and distressing consultations. A significant minority of GPs oppose abortion on moral grounds. Although fewer do so in practice, many women end up in mutually uncomfortable initial consultations with doctors who do not refer out of principle or are unhappy to refer. Many GPs in this study also expressed uncertainty about referring under-16s. This is important given that very young women are disproportionately represented in late abortion statistics and there are recognised variations in their use of abortion services. ${ }^{21}$ It is therefore necessary to develop and evaluate alternative pathways to abortion care, including self-referral and referral via other professionals such as school nurses. ${ }^{18}$

\section{Conclusions}

The NHS is failing to meet a national standard on access to abortion care for more than half of women referred. As well as recognised problems 'downstream' in secondary care, delays occur 'upstream' in primary care - largely because of attitudinal and organisational factors. Whilst marginal improvements can be made at both ends of the care pathway, it is time to promote and evaluate alternative approaches that bypass traditional gatekeepers.

\section{Acknowledgements}

The authors are grateful to the doctors and women who participated in this study, and to Greg Rubin and the anonymous referees for helpful comments on earlier versions of this manuscript.

\section{Statements on funding and competing interests}

Funding. Sarah Finnie was funded by a Northern Primary Care Research Network bursary, although the views expressed in this paper are those of the authors alone.

Competing interests. None identified.

\section{References}

1 Department of Health. http://www.dh.gov.uk/PolicyAndGuidance/ HealthAndSocialCareTopics/SexualHealth/fs/en [Accessed 3 December 2004].

2 Buehler JW, Schulz KF, Grimes DA, Hogue CJ. The risk of serious complications from induced abortion: do personal characteristics make a difference? Am J Obstet Gynecol 1985; 153: 14-20.
3 Ferris LE, McMain-Klein M, Colodny N, Fellows GF, Lamont J. Factors associated with immediate abortion complication. Can Med Assoc J 1996; 154: 1677-1685.

4 Department of Health. The National Strategy for Sexual Health and HIV. Implementation Action Plan. London, UK: Department of Health, 2002.

5 Royal College of Obstetricians and Gynaecologists (RCOG). The Care of Women Requesting Induced Abortion (National GuidanceBased Clinical Guideline No. 7). London, UK: RCOG Press, 2000.

6 Royal College of Obstetricians and Gynaecologists (RCOG) Clinical Effectiveness Support Unit. National Audit of Induced Abortion 2000. Report of England and Wales. London, UK: RCOG, 2001. http://www.rcog.org.uk/resources/public/pdf/nataudit_iabortion_200 $0 . p d f$ [Accessed 11 October 2005]

7 Zapka JG, Lemon S, Peterson LE, Palmer H, Goldman MB. The silent consumer. Women's reports and ratings of abortion services. Med Care 2001; 39: 50-60.

8 Francome C, Freeman E. British general practitioners' attitudes toward abortion. Fam Plann Perspect 2000; 32: 189-191.

9 Foy R, Penney GC, Grimshaw JM, Ramsay CR, Walker AE, MacLennan $\mathrm{G}$, et al. A randomised controlled trial of a tailored, multi-faceted strategy to promote implementation of a clinical guideline on induced abortion care. Br J Obstet Gynaecol 2004; 111: 726-733.

10 Altman DG, Machin D, Bryant T, Gardner M. Statistics with Confidence. London, UK: BMJ Books, 2000.

11 Office for National Statistics. 2003. http://www.statistics.gov.uk.

12 Penney GC, Glasier A, Templeton A. Patients' views on abortion care in Scottish hospitals. Health Bull 1994; 52: 431-435.

13 Healthcare Commission. http://www.healthcarecommission.org.uk/ InformationForServiceProviders/PerformanceRatings/fs/en [Accessed 11 October 2005].

14 Kumar U, Baraitser P, Morton S, Massil H. Decision making and referral prior to abortion: a qualitative study of women's experiences. J Fam Plann Reprod Health Care 2004; 30: 51-54.

15 Harden A, Ogden J. Young women's experiences of arranging and having abortions. Sociol Health Illn 1999; 21: 426-444.

16 Kennedy A. Living with a Secret. Perspectives on the Termination of Pregnancy Service in Glasgow. Glasgow, UK, fpa Scotland, 2002.

17 Lowy A, Ojo R, Stegeman A, Vellacott I. Meeting women's need for a flexible abortion service: retrospective study of a specialist day-care unit. J Public Health Med 2004; 20: 449-454.

18 Department of Health. Effective Commissioning of Sexual Health and HIV Services. A Sexual Health and HIV Commissioning Toolkit for Primary Care Trusts and Local Authorities. London, UK: Department of Health, 2003. http://www.dh.gov.uk/assetRoot/ 04/01/97/04/ 04019704.pdf [Accessed 11 October 2005].

19 Department of Health. A First Class Service. Quality in the New NHS. London, UK: Department of Health, 1998. http://www.dh. gov.uk/PublicationsAndStatistics/Publications/PublicationsPolicyAn dGuidance/PublicationsPolicyAndGuidanceArticle/fs/en?CONTEN T_ID=4006902\&chk=j2Tt7C [Accessed 11 October 2005].

20 Department of Health. A Responsive and High-quality Local NHS: The Primary Care Progress Report 2004. London, UK: Department of Health, 2004. http://www.dh.gov.uk/PublicationsAndStatistics/ Publications/PublicationsPolicyAndGuidance/PublicationsPolicyAn dGuidanceArticle/fs/en?CONTENT_ID=4079396\&chk=k3NGcn [Accessed 11 October 2005].

21 Lee E, Clements S, Ingham R, Stone N. A Matter of Choice? Explaining National Variations in Teenage Abortion and Motherhood. York, UK: York Publishing Services, Joseph Rowntree Foundation, 2004 